\title{
Do patients with obstructive sleep apnea have an increased risk of COVID-19 complications?
}

\author{
Mohammad Rasoul Ghadami ${ }^{1}$ \\ ${ }^{1}$ Kermanshah University of Medical Sciences
}

May 6, 2020

\begin{abstract}
* Patients with obstructive sleep apnea (OSA) and lung disease have more prominent nocturnal hypoxemia.

* Nocturnal hypoxemia in patients with impaired lung function with co-morbid OSA can enhance the possible mechanisms through which presence of OSA has been associated with adverse outcomes

* Hypoxemia-, sympathetic over-activation-, increased oxidative stress-, and systemic inflammation-related to OSA may exaggerate symptoms associated with COVID-19.

* It can be suggested that presence of OSA may plays a role in the severity of symptoms associated with COVID-19.

* Further investigation in COVID-19 patients with previous diagnosis of OSA is warranted.
\end{abstract}

\section{Hosted file}

OSA and COVID - Copy.doc available at https://authorea.com/users/318331/articles/448261-dopatients-with-obstructive-sleep-apnea-have-an-increased-risk-of-covid-19-complications 